terminal level of $P\left(A_{1}\right)$ was identical. The number of $A_{1}$ responses in each block of 20 trials (Table 1) was examined in a repeated measures analysis of variance. The $\mathbf{P}\left(\mathrm{A}_{1}\right)$ for Group EXP and Group REW was consistently higher than that of Group CONT. The Reward by Trials interaction was not statistically significant $(F=0.671, d f=10 / 165, p>.05)$. With the Group REW and the Group EXP data combined, the $F$ value increased, but not to a statistically significant level $(F=1.361, d f=5 / 170, p>.05)$. These measures of overall learning performance indicated that the combined Group REW and $\operatorname{EXP} P\left(A_{1}\right)$ were higher than the $P\left(A_{1}\right)$ for Group CONT. However, the differences again were not reliable.

The differences observed in $P\left(A_{1}\right)$ indicate that the children who only observed classmates return with toys performed in an experimental task like children who actually did receive rewards. These results were consistent with the results of classroom studies by Auble \& Mech (1953). Auble and Mech concluded that children, in the presence of positive reinforcement, mediated the reward effect, or were affected, in the same way as the children who actually received the reinforcement.

Inspection of the rank order of the intratask measures in Table 2 indicated that the major shift in the groups was with respect to a lose-shift response strategy. The differences between the strategy probabilities was tested using a chi-square analysis described by Tate \& Clelland (1957). The only significant $\chi^{2}$ value was associated with the lose-shift strategy. The children in the expectancy condition shifted responses more. They also were more variable throughout the probability learning task. Offenbach (1968) interpreted increases in response variability (as indicated by alternations) as reflecting a less effective use of the information available in the task. This also appeared to be the case here. Children who expected reward and failed to receive it did not pay close attention to the task. Thus they did not utilize all of the information available. Such an interpretation is consistent with the differences observed in the overt extratask behavior of the children.

The extratask behavior by the children in the three groups differed markedly. The Group CONT children were moderately active and talkative, but their behaviors did not interfere with the testing session. The Group REW children, on the other hand, were noisy, excited, and had to be told to quiet down several times during the experimental session. These children behaved as though they thoroughly enjoyed the game and the testing session.
Group EXP children were altogether different. They were noisy when they entered the lab and heard the instructions concerning the game. As the task started and nothing was mentioned about toys, the children looked confused and uncertain. They became very quiet and noncommunicative. Verbal behavior diminished sharply, and several of the children indicated a reluctance to continue with the experiment. The children later indicated that they were disappointed when they realized that they were not going to get any toys. These reactions indicated that the children were well aware of the unmentioned and unexplained change in the procedure of the experiment.

These results indicated that care must be taken in experimental tasks with tangible reward since most children would be aware, in some general way, of the reinforcement contingencies. If the children are given some trinket after the experimental session, their motivational state may be quite different, during the task, from that of a child who received reward immediately. If the children received the reward at the beginning of the experimental session or were informed of the reward contingencies immediately, response variability might be minimized. Thus another source of error variance could be reduced or eliminated. REFERENCES

AUBLE, D., \& MECH, E. V. Quantitative studies of verbal reinforcement in classroom situations: I. Differential reinforcement related to the frequency of error and correct responses. Journal of Psychology, 1953, 35, 307-312.

BRACKBILL, Y., KAPPY, M. S., \& STARR, R. H. Magnitude of reward and probability learning. Journal of Experimental Psychology, 1962, 63, 32-35.

MISHEL, W. Theory and research on the antecedents of self-imposed delay of reward. In B. A. Maher (Ed.), Progress in experimental personality research. Vol. 3. New York: Academic Press, 1966. Pp. 85-132.

OFFENBACH, S. I. Studies of children's probability learning behavior: I. Effect of reward and punishment at two age levels. Child Development, 1964, 35, 709-715.

OFFENBACH, S. I. Studies of children's probability learning behavior: VI. Effect of event sequences. Journal of Experimental Child Psychology, 1968, 6, 460-469.

RENNER, K. E. Delay of reinforcement: A historical review. Psychological Bulletin, 1964, 61, 341-361.

SIEGEL, S., \& ANDREWS, J. A. Magnitude of reinforcement and choice behavior in children. Journal of Experimental Psychology, 1962, $63,337-341$.

TATE, M. W., \& ClEllaND, R. C. Nonparametric and shortcut statistics. Danville: Interstate Press, 1957.

\section{NOTE}

1. This study was supported, in part, by a grant from the National Institute of Child Health and Human Development (HD-01639). The author would like to thank Mr. Roger Campbell, Principal of the Hillcrest Elementary School, Delphi, Indiana, for his cooperation in providing children to serve as Ss in this study.

\title{
Dual process of serial learning
}

\author{
ROBERT M. SCHWARTZ, University of \\ British Columbia, Vancouver 8, B.C., \\ Canada
}

Using a combination of traditional chaining and position paradigms, a dual process of serial learning was tested. The design included a transfer from a serial to a paired-associate task in which both chaining and position cues were available. The results suggest that a dual process exists in serial learning, but no attempt was made to determine the exact nature of that dual process.

The effective stimulus in serial learning has traditionally been tested by two paradigms. The most common paradigm testing a chaining hypothesis involves transfer from a serial list to a double-function paired-associate list (e.g., Young, 1961, 1962) in which the stimulus-response pairs are composed of successive couplets taken from the serial list. Use of this paradigm generally finds 
positive transfer only in the first or last positions of the serial list. The most common paradigm testing an ordinal hypothesis involves transfer from a serial to a paired-associate task in which the stimulus is the ordinal position of the word represented by digits or spatial discrimination cues. Use of this paradigm (e.g., Ebenholtz, 1963; Jensen \& Rohwer, 1965) has produced greater transfer than the chaining paradigm.

Young (1962) and Ebenholtz (1963) have proposed dual-process hypotheses of serial learning. Young, using the chaining paradigm, suggested that position learning occurs in the middle of a serial list and that chaining occurs at the extremes. Ebenholtz, using a position paradigm, suggested a dual process with position learning at the extremes and chaining in the middle. Neither Young nor Ebenholtz has used a paradigm that would simultaneously test both chaining and position learning; the present study suggests such a paradigm. The design was derived from Slamecka's (1964) study of remote associations. Slamecka first presented Ss with consecutively numbered serial lists, then transferred his Ss to a derived serial list. The words in the derived serial list retained the numbers from the original serial list.

\section{DESIGN}

Three serial lists were used; all three lists contained 10 words and were successively numbered from 1 to 10 . Serial Lists 1 and 2 ( $\mathrm{Sr} 1$ and $\mathrm{Sr} 2$ ) contained the same words, but the eight middle words were in different positions in the two lists. Serial List 3 (Sr3) contained 10 completely different words. Two paired-associate lists were used; the words in the paired-associate lists were the words used in Serial Lists 1 and 2. Paired-Associate List 1 (PA1) had the same stimulus cues as Serial List 1; Paired-Associate List 2 (PA2) had number cues that preceded the response in Serial List 2 and word cues that preceded the response in Serial List 1.

All combinations of one serial list followed by one paired-associate list were used. The six groups thus produced were given two labels (e.g., PN). The label in the first position indicates whether the number cue is positive or negative [defined in terms of whether it preceded the response $(\mathrm{P})$ or did not precede the response $(\mathrm{N})$ in the serial list]; the label in the second position indicates whether the word cue is positive or negative. Transfer from Srl to PAl is called Group PP; from $\mathrm{Sr} 2$ to PA1, Group NN; from Sr1 to PA2, Group PN; from Sr2 to PA2, Group NP; from Sr3 to PA1, the control group for PP and NN (C1); and from Sr3 to PA2, the control group for PN and NP (C2).

\section{MATERIALS}

All words in all lists were five-letter, two-syllable adjectives. No words within a list had the same initial letter. Both serial and paired-associate lists were presented on a standard memory drum. No starting symbol was used with this first list.

\section{PROCEDURE}

Serial lists were presented at a 2 -sec rate with a 4-sec intertrial interval. Paired-associate lists were presented at a $2: 2$ rate with a 4 -sec intertrial interval; there were three different orders of presentation of the pairs.

For the serial task, Ss were read typical serial instructions and run to a criterion of two consecutive perfect recitations. For the paired-associate list, Ss were read standard anticipation instructions and informed that there was a two-element stimulus consisting of both a word and a number. Ss were not informed of the relationship between the serial and paired-associate lists. All Ss were run 10 trials.

\section{SUBJECTS}

One hundred first- and second-year University of British Columbia undergraduates, mostly from introductory psychology classes, were recruited to form four groups of $20 \mathrm{Ss}$ each $(\mathrm{PP}, \mathrm{NN}, \mathrm{PN}$, $\mathrm{NP})$ and two groups of $10 \mathrm{Ss}$ each (C1 and C2).

\section{RESULTS \\ Serial Lists}

An analysis of variance $[F(2,97)<1$, $p>.05]$ showed that the three serial lists did not differ significantly in trials to criterion. The mean trials for the three lists were 15.38 (PP and PN), 15.95 (NN and NP), and 14.95 (C1 and C2).

\section{Transfer Lists}

Mean correct for the paired-associate tasks over 10 trials was 47.40 (PP), 18.05 (NN), 21.05 (PN), 23.50 (NP), 17.50 (C1) and 22.50 (C2). Comparing first and second list learning over all 10 trials, an analysis of variance yielded a significant main effect of serial list learning

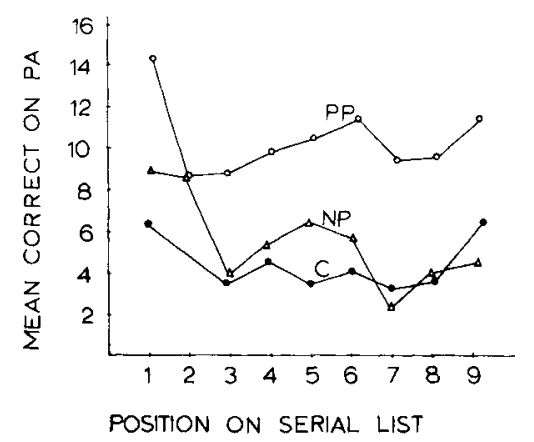

Fig. 1. Serial position curves for transfer task.
$[F(2,94)=6.5, p<.01]$, a significant main effect of paired-associate learning $[F(2,94)=10.5, p<.01]$, and a significant interaction between lists $[F(2,94)=11.3$, $\mathrm{p}<.01]$. A Duncan multiple-range test was used to make all pairwise comparisons. Group PP was found to make significantly $(p<.01)$ fewer errors than any of the other groups. No other differences were found.

Serial position curves for the paired-associate list for Groups PP, NP, and combined control are graphed in Fig. 1. From this graph, it is obvious that Group PP showed performance superior to the control group over all serial positions. DISCUSSION

Defined in terms of traditional transfer paradigms, positive transfer in only the $\mathbf{P P}$ group tends to support a dual-process hypothesis of serial learning. The failure to find positive transfer in Groups PN or NP can be attributed to the fact that $S s$ in these groups had both a positive and a negative cue. On the basis that both these groups had negative cues available and neither showed transfer, no reflection can be made on the relative strengths of the number and word cues. Failure to find negative transfer in Group NN was somewhat surprising and embarrassing. The only apparent explanation is that having two negative cues made the $S$ more aware of the negative nature of the transfer task. However, Postman \& Stark (1967) found that informing Ss of the negative nature of a traditional serial to paired-associate task did not benefit performance on the paired-associate task.

In conclusion, the evidence presented lends support to a dual-process hypothesis, but from the data and design the exact nature of this dual process cannot be determined. It is hoped that further use and modifications of this paradigm may lead to a refined description of the dual process in serial learning.

\section{REFERENCES}

EBENHOLTZ, S. M. Position mediated transfer between serial learning and a spatial discrimination task. Journal of Experimental Psychology, 1963, 65, 603-608.

JENSEN, A. R., \& ROHWER, W. D. What is learned in serial learning. Journal of Verbal Learning \& Verbal Behavior, 1965, 4, 62-75.

POSTMAN, L., \& STARK, K. Studies of learning to learn: IV. Transfer from serial to paired-associate learning. Journal of Verbal Learning \& Verbal Behavior, 1967, 3, 339-353.

SLAMECKA, N. J. An enquiry into the doctrine of remote associations. Psychological Review, $1964,71,61-76$.

YOUNG, R. K. The stimulus in serial verbal learning. American Journal of Psychology, $1961,74,517-528$.

YOUNG, R. K. Tests of three hypotheses about the effective stimulus in serial learning. Joumal of Experimental Psychology, 1962, 67, 307-313. 